\title{
Development and Evaluation of the Operational Parameters of a Rotary Oven
}

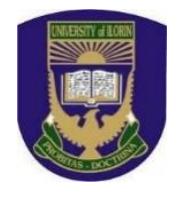

\author{
M. S. Sanusi ${ }^{1 *}$, M. O. Sunmonu ${ }^{1}$, A. L. Adepoju ${ }^{1}$, T. O. Abodunrin ${ }^{2}$,H. A. Ajibade ${ }^{1}$ \\ ${ }^{1}$ Department of Food Engineering, University of Ilorin, Ilorin Nigeria. \\ ${ }^{2}$ Department of Food Engineering, Ladoke Akintola University of Technology, Ogbomoso, Nigeria.
}

ABSTRACT: Developing an efficient rotary oven that is capable of addressing the issue of long baking duration and uneven heating distribution during baking could aid in encouraging indigenous use of the oven by small and medium scale bakeries in developing countries. This study aimed to develop and evaluate the performance of a rotary oven. Taguchi experimental design was used to investigate the influence of oven temperature $\left(160,180,200^{\circ} \mathrm{C}\right)$ and oven rack speed $(0,10,20 \mathrm{rpm})$ on the physical properties (baking time, mass, surface area, specific volume and density) of bread produced from the rotary oven. The baking capacity and efficiency of the rotary oven were $16 \mathrm{~kg} \mathrm{~h}^{-1}$ and $94 \%$, respectively. Investigation showed that baking time ranges from 20 to $82 \mathrm{~min}$, bread mass ( 884 to $925.7 \mathrm{~g}$ ), surface area $\left(1050\right.$ to $\left.1370 \mathrm{~cm}^{2}\right)$, specific volume $\left(2.36\right.$ to $\left.3.70 \mathrm{~cm}^{3} \mathrm{~g}^{-1}\right)$ and density $\left(0.25\right.$ to $\left.0.39 \mathrm{~g} \mathrm{~cm}^{-3}\right)$, respectively. The optimum baking time $(20 \mathrm{~min})$ was achieved at $200^{\circ} \mathrm{C}$ oven temperature and $10 \mathrm{rpm}$ oven rack speed. The oven could be adopted for both domestic and industrial production of bread and other bakery products.

KEYWORDS: Bread, oven temperature, oven rack speed, taguchi, rotary oven.

[Received November 15, 2019, Revised May 22, 2020, Accepted August 24, 2020]

Print ISSN: 0189-9546 | Online ISSN: 2437-2110

\section{INTRODUCTION}

Oven is one of the key food processing equipment that uses complex simultaneous heat and mass transfer process in the food industries. It is a thermally insulated chamber used for heating, baking, cooking, or drying of food substances (Monda and Datta, 2009; Adegbola et al., 2012). Baking is a widely used processing technique that plays an important role in determining the quality of the final product. Bread, cakes, biscuits, brownies, casseroles, cookies, pastries, puddings and tarts are examples of baked products. For efficient baking, there must be minimal moisture loss. According to Morakinyo et al. (2017), during baking, the driving force of heat transfer is the temperature gradient while that of mass diffusion is concentration difference. The heat and mass transfer occur simultaneously within the baked food material from the outer part to the inner part of the food material. The moisture diffusion while baking the food material occurs mainly by convection and conduction, less by radiation (Basil and Blessant, 2014). The quality of baked products is usually affected by the time and temperature of the baking process (Mondal and Datta, 2008). During baking, different changes such as volume expansion and crust formation occur in the dough depending on time and temperature (Therdthai et al., 2002).

The development of rotary oven has received considerable attention over the last decade, due to its durability, flexibility and efficiency. Unfortunately, in developing countries, the largescale bakers utilize the imported rotary ovens, which are unaffordable to small-scale or household bakers. Also, most of the existing baking oven used by small-scale bakers takes

\footnotetext{
*Corresponding author: sanusi.ms@unilorin.edu.ng
}

much time causing long waiting time for the users to have their product ready. Also, their efficiency is usually low with uneven distribution of heat which causes non-uniformity in baking, heat loss through the frequent opening of the oven door while monitoring the baking process and absence of an alarm system that indicates the end of the baking process. Several researchers have attempted to design different types of ovens; Adegbola et al. (2012), designed, constructed and evaluated the performance of low-cost electric baking oven; Ganitha et al. (2014), designed, fabricated and evaluated the performance of domestic gas oven; Okafor (2014) designed a dual powered domestic oven; Morakinyo et al. (2017), developed gas-fired tube oven while Chukwuneke et al. (2018) designed and fabricated dual-powered electric oven. Despite this tremendous effort made by several researchers, there is still paucity of information on the design of rotary oven. Little attention had been paid towards incorporating rotating rack inside an oven. Most researchers used stationary rack in their oven design to address non-homogenous heat distribution and longer baking time issues that were reported by Aborisade and Adewuyi (2014) and Morakinyo et al. (2017) as the shortcomings of the indigenous baking oven.

Taguchi Orthogonal Array (TOA) is a mathematical and statistical technique that is useful for evaluating, improving, and optimizing processes (Sanusi et al., 2020). It is widely used to examine the interactions among process parameters. Many researchers have used this method to optimize factors in food processing (Barua et al., 1997; Mecit et al., 2007; ChaoChin Chung et al., 2008; Ho-Hsien Chen et al., 2011; Chandrasekar et al., 2015; Sanusi et al., 2020). However, literature is sparse on development of a prototype of an electric doi: http://dx.doi.org/10.4314/njtd.v17i4.1 
rotary oven which can be used in developing countries. Also, only few studies have focused on studying the effect of oven temperature and oven rack speed on some physical properties of bread produced from the rotary oven. Therefore, this study aimed to develop and evaluate the performance of a rotary oven. The study was further extended by using Taguchi technique to determine the influence of oven temperature and oven rack speed on the physical properties (baking time, bread mass, bread volume, surface area, specific volume and density) of bread baked in the developed rotary oven.

\section{MATERIALS AND METHODS}

\section{A. Design Consideration}

The parameters considered in the design of the rotary oven were selected based on the following factors:

i. Sanitary and hygienic properties of the material: construction material that may come in contact with food must be corrosion resistant, must be inert to the food material under its operating conditions and must be nontoxic. Therefore, AISI 304 stainless steel was used for the inner chamber of the oven while mild steel is used for the outer chamber.

ii. Availability of the material and cost: the availability of AISI 304 stainless steel, mild steel and overall cost were considered through critical value analysis in material selection, design and production which will make it affordable to users.

iii. Strength and durability of the material: factors such as; strength, durability, stability, vibration were considered in the selection of appropriate materials for the various components of the oven.

iv. The convenience of use during production: The userfriendly interface between the operator and the oven were considered, i.e. ease of operation, convenient handling, the safety of the operator and those within the area of operation of the machine.

\section{B. Design Calculations}

1.) Rotary oven and chamber wall: The dimensions that were used for the design of the rotary oven are shown in the orthographical view in Figure 1.

\section{2.) Volume of oven baking chamber}

The baking oven chamber is the enclosed chamber where the baking takes place and the volume was calculated using Eq. (1) as described by Clements et al. (2001).

$$
V=B C L \times B C W \times B C H
$$

where $V$ is the volume of the baking chamber $\left(\mathrm{mm}^{3}\right), B C L$ is the baking chamber length, $B C W$ is the baking chamber width and $B C H$ is the baking chamber height.

Therefore, the volume of the baking chamber $(V)$ is equivalent to $0.285 \mathrm{~m}^{3}$, given the values of $560 \mathrm{~mm}, 520 \mathrm{~mm}$ and $980 \mathrm{~mm}$ for $B C L, B C W$ and $B C H$ respectively.

\section{3.) Capacity of the oven}

The capacity of the oven is the number of loaves of bread that can be baked in the oven per batch. The capacity of the oven was determined using Eq. (2) as described by Okafor (2004).

Assuming only 1 oven rack tray;

The average mass of bread dough $=0.950 \mathrm{~kg}$

Area of the rack tray $=300 \mathrm{~mm}$ (length) $\times 250 \mathrm{~mm}$ (width) $=75,000 \mathrm{~mm}^{2}$.

Area of loaf of bread considered $=150 \mathrm{~mm}$ (length) $\times 150$ $\mathrm{mm}($ width $)=22,500 \mathrm{~mm}^{2}$.

$$
\mathrm{CO}=\frac{\mathrm{SRT}}{\mathrm{SB}}
$$

where $C O$ is capacity of oven, $S R T$ is size of rack tray and $S B$ is size of bread.

Therefore, $C O$ is equivalent to 3 loaves of bread per rack tray. The oven has three (3) compartments for rack trays which is equivalent to 9 loaves of bread per batch.

\section{4.) Electric energy requirement}

The heat required was calculated using Eq. (3) (Anyakoha, 2013).

$$
Q_{H}=M_{b} \times C_{b} \times T_{d}
$$

where $M_{b}$ is mass of bread, $C_{b}$ is specific heat capacity of bread and $T_{d}$ is difference in temperature.

The average oven baking temperature was $200{ }^{\circ} \mathrm{C} \equiv 473.15 \mathrm{~K}$; mass of bread is $0.950 \mathrm{~kg}$; Specific heat capacity of bread is $2890 \mathrm{~J} \mathrm{~kg}^{-1} \mathrm{~K}^{-1}$ according to Zheleva and Kambourova, (2005); Oven room temperature is $27{ }^{\circ} \mathrm{C} \equiv 300.15 \mathrm{~K}$. Therefore, the quantity of heat required to bake 9 loaves of bread per batch, $\mathrm{Q}_{\mathrm{H}}$ is calculated as 4,274,743.5 Joules.

\section{5.) Airflow required}

The airflow rate (AF) was calculated using Eq. (4) (Falke, 2016). An air change of $5 \mathrm{~m}^{3} \mathrm{~min}^{-1}$ was assumed since the value was within the recommended for baking oven design.

$$
A F=U \times V
$$

where $U$ is air changed $\left(\mathrm{m}^{3} \mathrm{~min}^{-1}\right)$ and $V$ is volume of the oven.

In other words, given the values of $0.285 \mathrm{~m}^{3}$ and $5 \mathrm{~m}^{3} \mathrm{~min}^{-1}$ for $V$ and $U$ respectively, the airflow rate $(A F)$ is $1.425 \mathrm{cfm}$.

\section{6.) The fan design}

The fan served the purpose of distributing heat by drawing ambient air from the collector to the heater housing and discharging heated air to the oven chamber. The fan horse power (FHP) was calculated using Eq. (5) (Engineering Tool Box, 2010).

$$
F H P=\frac{A F \times P R}{6320 \times F E}
$$



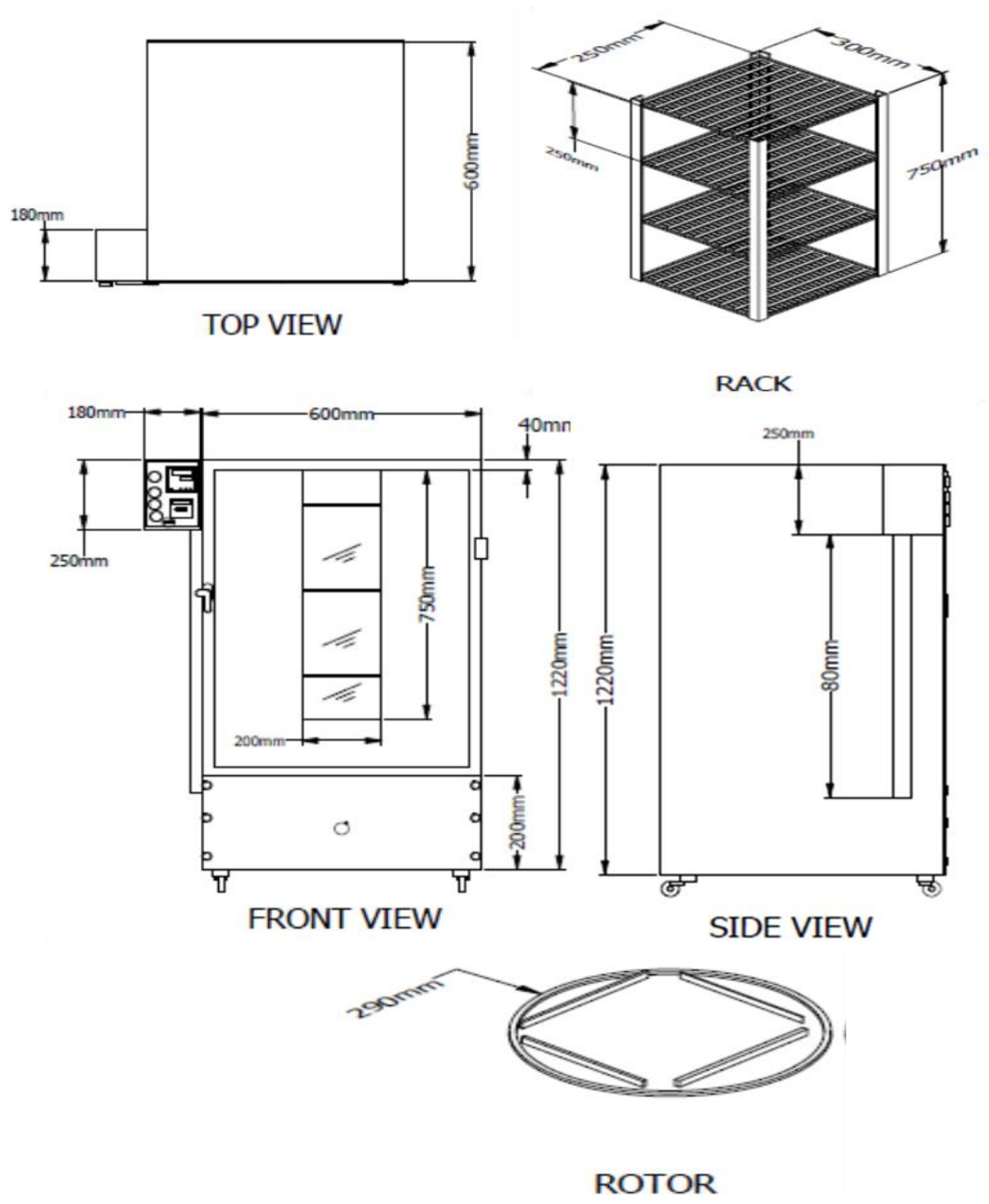

Figure 1: Orthographic view of the rotary oven.

where $P R$ is pressure rise from fan, $F E$ is fan efficiency

From literature, most industrial fans have efficiency ranging from $70-85 \%$. Assuming a fan with an efficiency of $85 \%$ and pressure rise from fan of $1136 \mathrm{mmWg}$ (Bureau of Energy Efficiency, 2005). The fan horse power $(F H P)$ was calculated to be $0.30 \mathrm{Hp}$, given the values of $1.425 \mathrm{cfm}, 1135 \mathrm{mmWg}$ and 0.85 for $A F, P R$ and $F E$ respectively.

Based on the above calculation, an axial flow fan with 0.5 Hp was selected. An axial flow fan was used to ensure proper distribution of air to the oven chamber and for effective heat distribution (Stadler et al., 2012). 


\section{7.) Capacity of the electric heating element}

Power (PHE) of the electric heating element was calculated using Eq. 6 (Okafor, 2014).

$$
\text { PHE }=\frac{E}{T}
$$

where PHE is the power of the electric heating element, $E$ is the energy and $T$ is average processing time per dough batch.

Assuming the average processing time per dough batch is 30 min, thus, from Eq. (3) the quantity of heat supplied to the oven chamber is $4,274,743.5 \mathrm{~J}$.

According to Le-bail et al. (2010), $1.2 \mathrm{~J} / \mathrm{g}$ of energy is needed to gelatinise starch in bread dough, therefore the heat transfer to the dough is equivalent to;

$$
H T D=E G S \times Q_{H}
$$

where $H T D$ is heat transfer to the dough and EGS is energy needed to gelatinise the starch in bread dough.

Therefore, the heat transfer to the dough (HTD) was calculated as 5129692.2 Joules, given the values of $1.2 \mathrm{~J} / \mathrm{g}$ and $4274743.5 \mathrm{~J}$ for $E G S$ and $Q_{H}$ respectively. This means that the heating element would supply a minimum of 5129692.2 Joules of heat energy to the oven chamber in $30 \mathrm{~min}$.

Thus, $\quad P H E=2849.83 \mathrm{~J} / \mathrm{sec} .=2849.83 \mathrm{~W}=2.85 \mathrm{~kW}$

Thus, power of electrical heating element of $3,000 \mathrm{~W}$ or 3 $\mathrm{kW}$ was selected.

In order to determine the resistance of the heating element and the current required to operate the oven, Eq. 8 and Eq. 9 were used according to Anyakoha (2013).

$$
P H E=\frac{V^{2}}{R}
$$

where $R$ is the electrical resistance $(\Omega), \mathrm{V}$ is voltage supply in Nigeria.

Thus from Eq. (8), the resistance of the heating element, $R$, is $20.2 \Omega$, given the values of $240 \mathrm{~V}$ and $2,849.83 \mathrm{~W}$ for $V$ and $P H E$ respectively.

The current required was calculated using Eq. (9).

$$
I=\frac{P H E}{V}
$$

The current required for the oven was determined to be 11.87 $\mathrm{A}$, given the values of $2849.83 \mathrm{~W}$ and $240 \mathrm{~V}$ for PHE and V respectively.

\section{8.) Selection of Electric Motor}

The selection of the motor was based on two parameters viz: i. Rotational speed ii. Power consumption

The oven assumes the use of a 3 amps 3 phase electric motor. McCable et al. (1985) approach was used to determine rotational speed as shown in Eq. (10).

$$
m g h=\frac{1}{2} m v^{2}
$$

where, $\mathrm{m}$ is mass of load on the rotor $(\mathrm{g}), \mathrm{g}$ is acceleration due to gravity $\left(9.8 \mathrm{~ms}^{-2}\right), h$ is height of load from the rotor $(0.1$ m) $v$ is speed of the rotor $\left(\mathrm{ms}^{-1}\right)$.

From Eq. (10), $v=\sqrt{2} g h$.

Therefore, the speed of the motor was calculated as $1.4 \mathrm{~ms}^{-1}$, given the values of $9.8 \mathrm{~ms}^{-2}$ and 0.1 for $\mathrm{g}$ and $\mathrm{h}$ respectively. For motor power $\left(\mathrm{P}_{\mathrm{m}}\right)$ consumption determination, Kirschen et al. (1985) was used using Eq. (11).

$$
P_{m}=V I \sqrt{3}
$$

The motor power consumption was calculated as $4928.42 \mathrm{~W}$ which is equivalent to $4.928 \mathrm{~kW}$, given the values of $240 \mathrm{~V}$, $11.87 \mathrm{~A}$ for $V$ and $I$ respectively. Therefore a motor with power consumption of $7 \mathrm{Hp}$ was selected.

\section{Performance Evaluation of the Rotary Oven}

Performance evaluation was carried out to determine the functionality and performance characteristics of the rotary oven. The performance evaluation characteristics were carried out to establish the optimum baking capacity and baking efficiency.

\section{1.) Baking capacity}

Morakinyo et al. (2017) approach was used to determine the baking capacity using Eq. 12. The baking capacity of the rotary oven was determined by putting into consideration the three (3) space in the rack compartment $(300 \mathrm{~mm} \times 250 \mathrm{~mm} \times$ $250 \mathrm{~mm})$ and the baking pan for bread dough $(150 \mathrm{~mm} \times 150$ $\mathrm{mm} \times 150 \mathrm{~mm})$. Nine (9) pieces of bread dough $(950 \mathrm{~g})$ each in the baking pan, occupied the rack compartment of the rotary oven and the optimum baking time was determined.

$$
B C=\frac{\mathrm{MD}}{\mathrm{BT}}
$$

where, BC is baking capacity, MD is mass of dough ( $\mathrm{kg})$ and $\mathrm{BT}$ is baking time (h)

\section{2.) Baking efficiency}

The baking efficiency of the rotary oven was determined by using the ratio of the designed baking time to the actual baking time required to bake a batch of dough to its desired taste, colour and texture in the rotary oven as calculated in Eq. 13 (Okafor et al., 2014).

$$
B E=\frac{\mathrm{DBT}}{\mathrm{ABT}}
$$


where, $B E$ is baking efficiency, $D B T$ is designed baking time (min), $A B T$ is actual baking time (min).

\section{Taguchi Experimental Design and Bread Dough Preparation}

Taguchi experimental design was used to evaluate the effect of oven temperature and oven rack speed using Minitab 16 statistical software package (U.K). Table 1 shows the Taguchi experimental design $\mathrm{L}_{9}\left(3^{2}\right)$. The bread preparation was carried out at the Department of Food Engineering, University of Ilorin, Nigeria. Bread dough was prepared by mixing $57.12 \%$ wheat flour, $7.65 \%$ sugar, $0.96 \%$ vegetable oil, $0.86 \%$ salt, $29.02 \%$ water, $1.83 \%$ milk, $0.69 \%$ yeast (Saccharomyces cerevisiae) and $1.87 \%$ margarine using a fabricated planetary dough mixer. The bread dough was divided, moulded into $950 \mathrm{~g}$ of six (6) pieces each and were placed inside clean and oiled baking pans $(150 \mathrm{~mm} \times 150 \mathrm{~mm}$ $\times 150 \mathrm{~mm}$ ).

The dough was proofed in a fabricated proofer at proofing temperature of $40^{\circ} \mathrm{C}$ for $45 \mathrm{~min}$. After the proofing process, the proofed dough was transferred and arranged on the oven rack trays inside the rotary oven and allowed to bake at a varying oven temperature of $160^{\circ} \mathrm{C}, 180^{\circ} \mathrm{C}$ and $200^{\circ} \mathrm{C}$ and oven rack speed of $0 \mathrm{rpm}$ (stationary), $10 \mathrm{rpm}$ and $20 \mathrm{rpm}$ based on Taguchi orthogonal array experimental designed. Nine (9) treatments at different conditions were obtained from Taguchi design and the bread obtained were analysed for the effect of oven temperature and oven rack speed on the physical properties (baking time, bread mass, bread surface area, specific volume and density).

Table 1: Experimental design using Taguchi $\mathrm{L}_{9}\left(3^{2}\right)$.

\begin{tabular}{cccc}
\hline Independent Variables & \multicolumn{4}{c}{ Treatment Levels } \\
\hline Oven temperature $\left({ }^{\circ} \mathrm{C}\right)$ & 160 & 180 & 200 \\
Oven rack speed $(\mathrm{rpm})$ & 0 & 10 & 20 \\
\hline 0 rpm means at the rack is at a stationary position
\end{tabular}

\section{2.) Baking time}

An instant-read thermometer (Model: DTH-81, Palermo) was used to measure the bread doneness. The thermometer was inserted into the centre of the loaf side at intervals. Digital stopwatch (Model: Fastime 20) was used to monitor the baking time and the baking was terminated at an internal thermometer reading of $210^{\circ} \mathrm{F}$ or $98^{\circ} \mathrm{C}$ (Martin, 2018). Baking time was recorded for each treatment.

\section{3.) Bread mass, specific volume and density}

The baked bread samples were weighed $1 \mathrm{~h}$ after baking using a digital weighing scale (Cammry, Model ACS-ZE21W, China) $\pm 0.01 \mathrm{~g}$ precision scale. At that point, the volume of the bread was measured by rapeseed displacement according to the American Association Cereal Chemists (AACC) method 10-05 (2001). The obtained results were used to determine the specific volume $\left(\mathrm{cm}^{3} \mathrm{~g}^{-1}\right)$ and density $\left(\mathrm{g} \mathrm{cm}^{-3}\right)$.

\section{4.) Bread surface area}

Bread surface area was calculated using Eq. 14 as described by Morakinyo et al. (2017). Parameters such as length (l), width (b) and height (h) were measured using a digital vernier caliper (Model AD-5765-100, China) having a sensitivity of $0.01 \mathrm{~mm}$.

$$
\begin{aligned}
& S A=2(l b+b h+l h) \\
& \text { where } S A \text { is the surface area }
\end{aligned}
$$

\section{E. Statistical Analysis}

All determinations were performed in triplicates $(n=3)$. All data were subjected to one-way analysis of variance (ANOVA) and means were separated using Duncan's Multiple-Range Test (DMRT) at $\mathrm{p} \leq 0.05$ using SPSS 20.0 software package (SPSS, Inc., U.K).

\section{RESULTS AND DISCUSSION}

\section{A. Description and Mode of Operation of the Rotary Oven}

A prototype of a rotary oven was developed for baking purpose. The rotary oven is a compact type of oven that uses the three modes of heat transfer (conduction, convection and radiation) to bake food products. Auto Inventor Professional 2017 (U.S) was used for drawing the orthographic, exploded and isometric projections of the rotary oven. Figures 2 and 3 showed the exploded and isometric view of the rotary oven. The exploded view of the rotary oven, which consists of the components parts used for oven. The major materials used for the construction of the rotary oven were: AISI 304 stainless steel for the construction of the interior chamber, mild steel for the construction of the exterior chamber, glass fibre was used for lagging the oven to prevent heat loss from the oven cavity and removable rack to hold food products to be baked.

The oven has a heat resistance glass door to enhance the ease of monitoring of product during the baking process. Heating element and fan are other key components of the oven. The speed of the fan varies automatically with the temperature of the heating element. The pressurized air from the fan is passed through the heating element and at the same time been heated before entering into the oven cavity where the baking takes place. A control panel meant for setting baking time, baking oven temperature and for regulating the speed of rotor that holds the removable rack was also incorporated. The timer was connected to an alarm system that indicates when the appropriate baking time and the temperature are reached. Also within the rotary oven is a thermostat that checks and helps regulate the temperature of the oven. The thermostat ensures the temperature within the oven does not exceed the set temperature by the operator. Plate 1 shows the picture of the rotary oven. 
B. Effect of Oven Temperature and Oven Rack Speed on Baking Time

Baking time is one of the key operational parameters used in evaluating the performance of an oven. Short baking time signifies an efficient oven with high production rate tendency. Figure 4 shows the surface plot of the effect of oven temperature and oven rack speed on baking time. The shortest baking time was $20 \mathrm{~min}$ at $200{ }^{\circ} \mathrm{C}$ oven temperature and 10 rpm oven rack speed while the longest baking time was $82 \mathrm{~min}$ and it occurred at an oven temperature of $160^{\circ} \mathrm{C}$ and oven rack speed of $0 \mathrm{rpm}$. Table 2, shows that baking time varies significantly at $\mathrm{p} \leq 0.05$. It was observed that as temperature increases, there was a reduction in the baking time. This could be attributed to an increase in temperature profile due to heat transfer, which accelerates baking rate, thus reduces the baking time. The results are in agreement with the findings of Ureta $e t$ al. (2016), that no matter the conventional mode of heat transfer, baking time decreases with an increase in oven temperature. Morakinyo et al. (2015) also observed a similar trend. However, an increase in oven rack speed from 0 to 10 rpm reduces baking time while an increase from 10 to $20 \mathrm{rpm}$ resulted into increase in baking time. This might be attributed to the steady rotation of oven rack at $10 \mathrm{rpm}$, which allows even distribution of hot air than at $20 \mathrm{rpm}$. Also, the rate of hot air penetration into the bread dough might decrease due to the increase in oven rack speed which could also result in the longer baking time observed at $20 \mathrm{rpm}$. Eq. 15 shows the quadratic regression model relating the effect of oven temperature and oven rack speed on baking time (BT).

$$
\begin{aligned}
& B T=860.668-7.554 x_{1}-10.133 x_{2}+0.017 x_{1}^{2}+ \\
& 0.047 x_{2}^{2}+0.048 x_{1} x_{2}
\end{aligned}
$$

where, $\mathrm{x}_{1}$ and $\mathrm{x}_{2}$ are oven temperature and oven rack speed. The coefficient of determination $\left(R^{2}\right)$ and $R^{2}(a d j)$ obtained for the model was $94.80 \%$ and $86.14 \%$. According to Peng et al. (2019), $R^{2}$ value of more than $75 \%$ is considered accurate in developing a statistical model. Also, Mazaheri et al. (2017) reported that the closeness between $R^{2}$ and $R^{2}{ }_{\text {(adj) }}$ values and the lower the value of $R^{2}$ (adj) compared to the $R^{2}$ value, for the model, indicates the goodness of data fit. Therefore, this model is fit to predict the influence of oven temperature and oven time on baking time.

\begin{tabular}{|c|c|c|c|c|c|c|}
\hline $\begin{array}{l}\text { Oven } \\
\text { temperature }\left({ }^{\circ} \mathbf{C}\right)\end{array}$ & $\begin{array}{l}\text { Oven rack } \\
\text { speed } \\
\text { (rpm) }\end{array}$ & Baking time (min) & Bread mass (g) & $\begin{array}{l}\text { Bread specific } \\
\text { volume }\left(\mathrm{cm}^{3} \mathrm{~g}^{-1}\right)\end{array}$ & Bread surface area $\left(\mathrm{cm}^{2}\right)$ & $\begin{array}{l}\text { Bread Density } \\
\left(\mathrm{g} \mathrm{cm}^{-3}\right)\end{array}$ \\
\hline 160 & 0 & $82.00 \pm 0.00^{\mathrm{a}}$ & $884.00 \pm 5.00^{\mathrm{c}}$ & $2.82 \pm 0.39^{\mathrm{cd}}$ & $1130.00 \pm 91.65^{\mathrm{de}}$ & $0.35 \pm 0.05^{\mathrm{ab}}$ \\
\hline 160 & 20 & $46.00 \pm 0.00^{\mathrm{c}}$ & $921.33 \pm 1.15^{\mathrm{ab}}$ & $2.36 \pm 0.00^{\mathrm{d}}$ & $1050.00 \pm 0.00^{\mathrm{e}}$ & $0.39 \pm 0.00^{\mathrm{a}}$ \\
\hline 180 & 0 & $38.33 \pm 2.89^{\mathrm{d}}$ & $925.33 \pm 5.03^{\mathrm{a}}$ & $2.72 \pm 0.06^{\mathrm{cd}}$ & $1136.00 \pm 12.49^{\text {cde }}$ & $0.34 \pm 0.01^{\mathrm{ab}}$ \\
\hline 180 & 20 & $41.67 \pm 2.89^{\mathrm{f}}$ & $921.33 \pm 1.16^{\mathrm{ab}}$ & $2.79 \pm 0.32^{\mathrm{cd}}$ & $1138.00 \pm 78.30^{\text {cde }}$ & $0.35 \pm 0.04^{\mathrm{ab}}$ \\
\hline 200 & 0 & $21.00 \pm 0.00^{\mathrm{gh}}$ & $923.67 \pm 3.06^{\mathrm{a}}$ & $3.51 \pm 0.08^{\mathrm{ab}}$ & $1340.00 \pm 17.32^{\mathrm{ab}}$ & $0.27 \pm 0.01^{\mathrm{c}}$ \\
\hline 200 & 10 & $20.00 \pm 0.00^{\mathrm{h}}$ & $916.33 \pm 3.06^{\mathrm{ab}}$ & $3.14 \pm 0.48^{\mathrm{bc}}$ & $1246.00 \pm 122.42^{\mathrm{bc}}$ & $0.30 \pm 0.05^{\mathrm{bc}}$ \\
\hline 200 & 20 & $23.67 \pm 1.15^{\mathrm{g}}$ & $911.00 \pm 13.86^{\mathrm{b}}$ & $2.88 \pm 0.15^{\mathrm{c}}$ & $1186.00 \pm 27.72^{\text {cd }}$ & $0.32 \pm 0.01^{\mathrm{b}}$ \\
\hline
\end{tabular}

Table 2: Effect of oven temperature and oven rack speed on the physical properties.

Mean values in the same column with the same superscript do not differ significantly at $\mathrm{p} \leq 0.05$

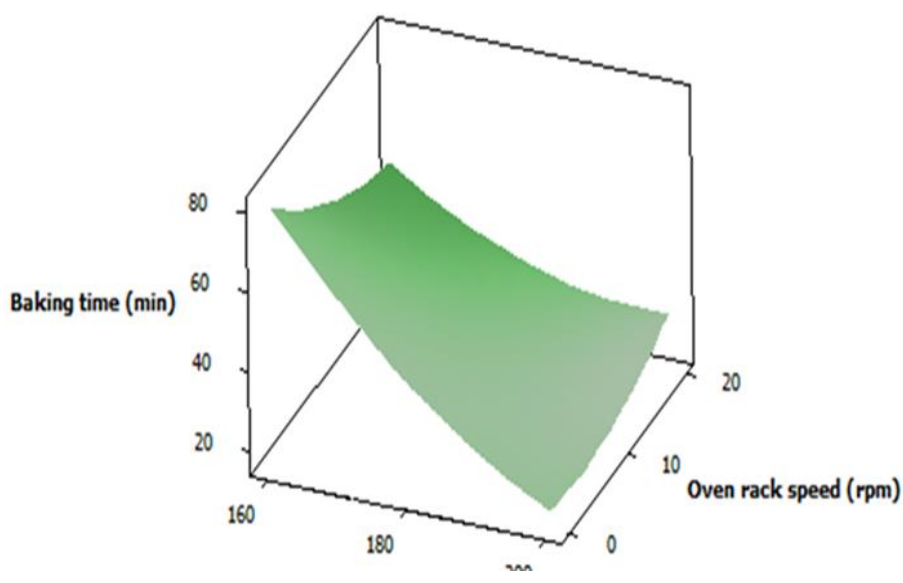

Figure 4: Surface plot of the effect of oven temperature and oven rack speed on baking time. 


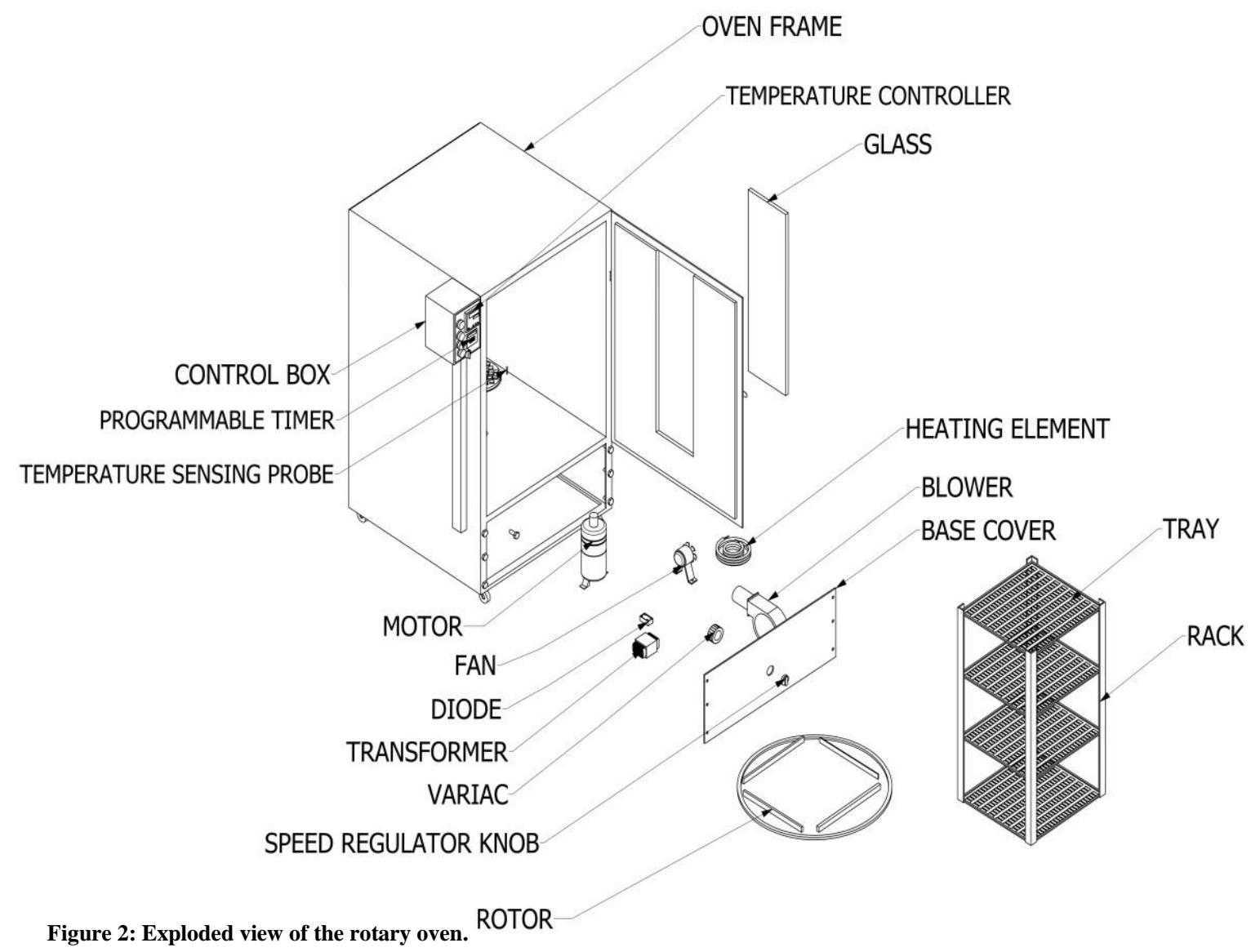

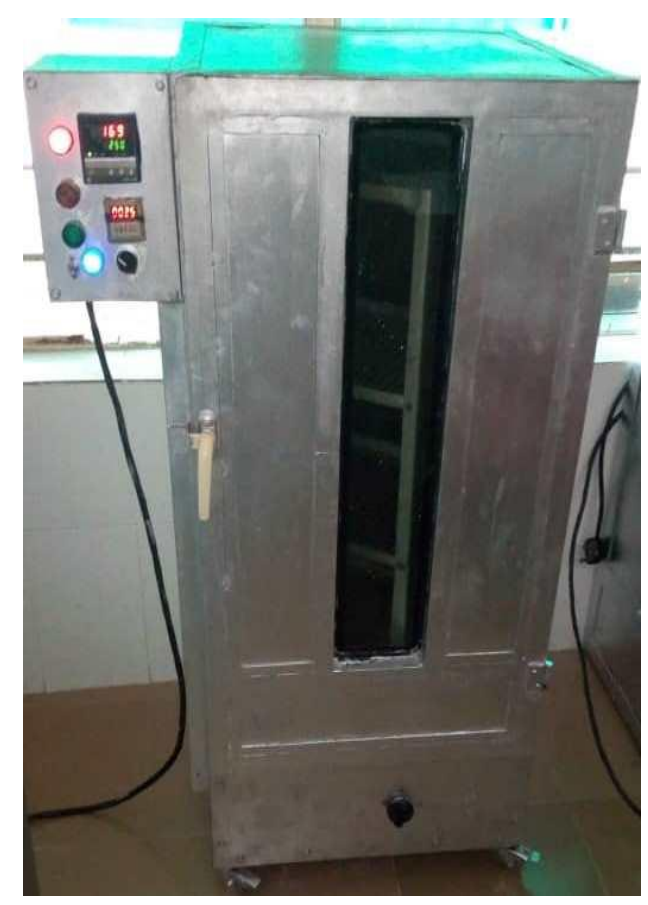

Plate 1: Picture of the rotary oven.

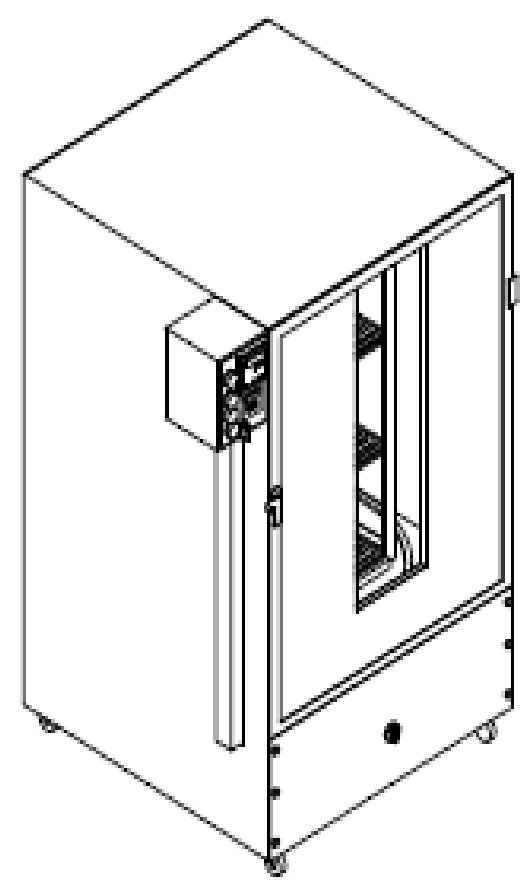

Figure 3: Isometric view of the rotary oven. 


\section{Effect of Oven Temperature and Oven Rack Speed on the Mass of the Baked Bread}

Bakers prefer bread with minimal weight loss that is why information on the mass is important. Figure 5 shows the surface plot effect of oven temperature and oven rack speed on the mass of baked bread under different conditions. The highest bread mass $(925.67 \pm 2.08 \mathrm{~g})$ was observed at $180^{\circ} \mathrm{C}$ oven temperature and $10 \mathrm{rpm}$ oven rack speed while the least bread mass $(884.00 \pm 5.00 \mathrm{~g})$ occurred at $160^{\circ} \mathrm{C}$ oven temperature and $0 \mathrm{rpm}$ oven rack speed. However, there was no much disparity (Table 2) between the bread mass $(916.33 \pm 3.06 \mathrm{~g})$ at $200^{\circ} \mathrm{C}$ oven temperature and $10 \mathrm{rpm}$ oven rack speed and the bread mass $(925.67 \pm 2.08 \mathrm{~g})$ at $180^{\circ} \mathrm{C}$ oven temperature and $10 \mathrm{rpm}$ oven rack speed. The difference in the bread mass could be as a result of moisture loss and increased baking time. As the baking time increases at lower oven temperature, there is a slow process of crust formation which leads to more moisture loss. Therefore, the rate of crust formation might also be responsible for the differences observed in the bread mass. These results corroborate the previous findings of Bahnasawy and Khater (2014) and Genitha et al. (2014) that as baking time increases, weight loss increase which further leads to mass loss. Eq. 16 shows the quadratic regression model relating the effect of oven temperature and oven rack speed on bread mass.

$$
\begin{aligned}
& \text { Bread mass }=-616.463+15.997 x_{1}+10.772 x_{2}- \\
& 0.041 x_{1}^{2}+0.041 x_{2}^{2}-0.063 x_{1} x_{2}
\end{aligned}
$$

where, $x_{1}$ and $x_{2}$ are oven temperature and oven rack speed. The coefficient of determination $\left(\mathrm{R}^{2}\right)$ and $\mathrm{R}^{2}$ (adj) obtained for the model was $90.79 \%$ and $75.44 \%$. Therefore, this model is capable of predicting the influence of oven temperature and oven rack speed on bread mass.

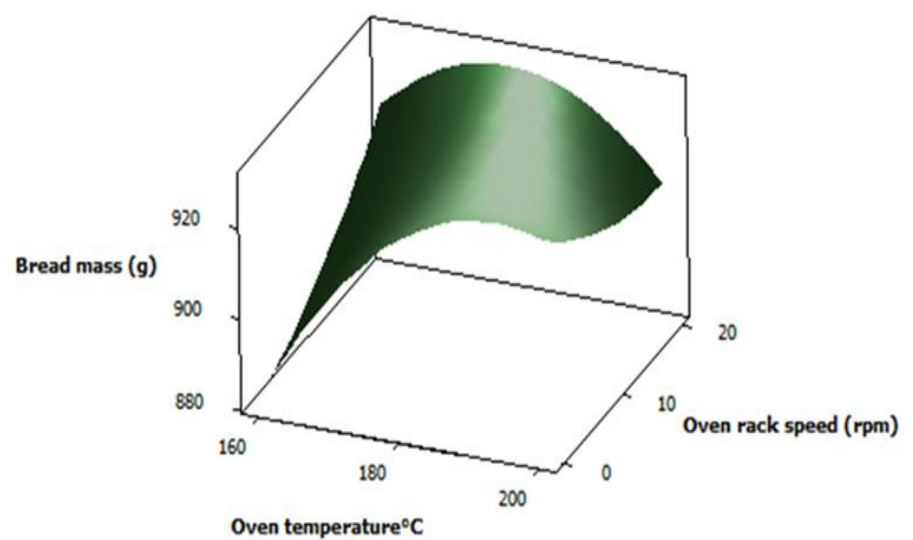

Figure 5: Surface plot of the effect of oven temperature and oven rack speed on bread mass.

\section{Effect of Oven Temperature and Oven Rack Speed on the Bread Surface Area}

Figure 6 shows the surface plot effect of oven temperature and oven rack speed on the surface area of the bread. It was observed that the minimum bread surface area $\left(1050.00 \mathrm{~cm}^{2}\right)$ was recorded at $160^{\circ} \mathrm{C}$ oven temperature and $20 \mathrm{rpm}$ oven rack speed, while the maximum bread surface area $(1370.00 \pm 34.64$ $\mathrm{cm}^{2}$ ) was achieved at an oven temperature of $160^{\circ} \mathrm{C}$ and oven rack speed of $10 \mathrm{rpm}$.

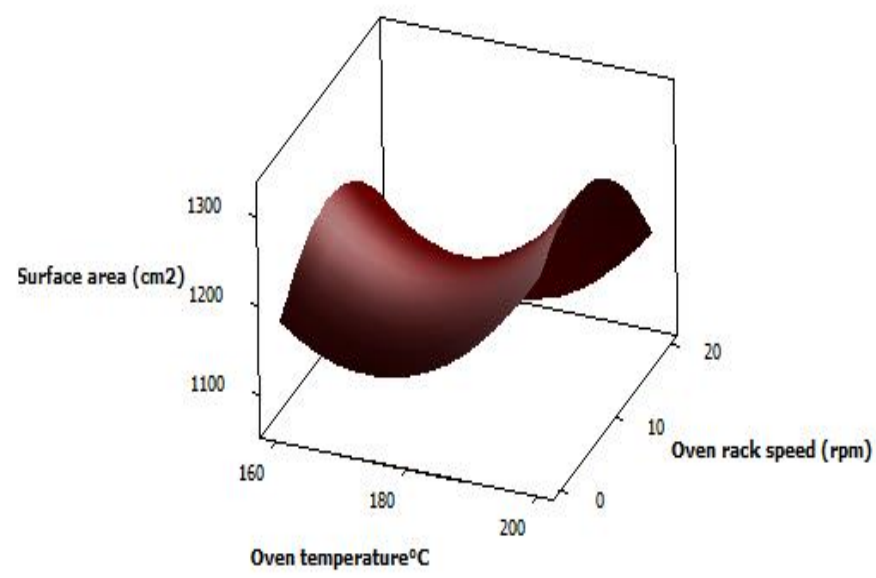

Figure 6: Surface plot of the effect of oven temperature and oven rack speed on bread surface area

However, there was no significant different $(p \leq 0.05)$ between the bread surface area $\left(1340.00 \pm 17.32 \mathrm{~cm}^{2}\right)$ observed at $200^{\circ} \mathrm{C}$ oven temperature and $0 \mathrm{rpm}$ oven rack speed and that of $160^{\circ} \mathrm{C}$ oven temperature and $10 \mathrm{rpm}$ oven rack speed. The oven spring and the rack rotation that occurred at the temperature might be responsible for the maximum surface area observed at the temperatures. Table 2 shows a significant difference in the baked bread surface area at different conditions. However, these results slightly agree with Morakinyo et al. (2017) findings which stated that maximum bread surface area was observed at $180^{\circ} \mathrm{C}$ rather than at $200^{\circ} \mathrm{C}$ while studying the performance of the developed gas-fired baking oven. Eq. 17 shows the quadratic regression model relating the effect of oven temperature and oven rack speed on the bread surface area.

$$
\begin{aligned}
& \text { Bread surface area }=7691.50-75.52 x_{1}+29.58 x_{2}+ \\
& 0.22 x_{1}^{2}+0.84 x_{2}^{2}-0.09 x_{1} x_{2}
\end{aligned}
$$

where, $x_{1}$ and $x_{2}$ are oven temperature and oven rack speed. The coefficient of determination $\left(\mathrm{R}^{2}\right)$ and $\mathrm{R}^{2}$ (adj) obtained for the model was $52.56 \%$ and $0.00 \%$. Therefore, this model is not fit to predict the effect of oven temperature and oven rack speed on the bread surface area. This could also imply that more factors aside oven temperature and oven rack speed could influence bread surface area. 


\section{E. Effect of Oven Temperature and Oven Rack Speed on the Bread Specific Volume}

Bread specific volume is one of the major qualitydetermining criteria for bread quality. Bread with a larger volume is always preferred. Figure 7 shows the surface plot of the effect of oven temperature and oven rack speed on the specific volume of baked bread. The least bread specific volume $\left(2.36 \pm 0.00 \mathrm{~cm}^{3} \mathrm{~g}^{-1}\right)$ was recorded at an oven temperature of $160{ }^{\circ} \mathrm{C}$ and oven rack speed of $20 \mathrm{rpm}$, while the highest specific volume $\left(3.70 \pm 0.13 \mathrm{~cm}^{3} \mathrm{~g}^{-1}\right)$ was recorded at an oven temperature of $160{ }^{\circ} \mathrm{C}$ and oven rack speed of 10 rpm.

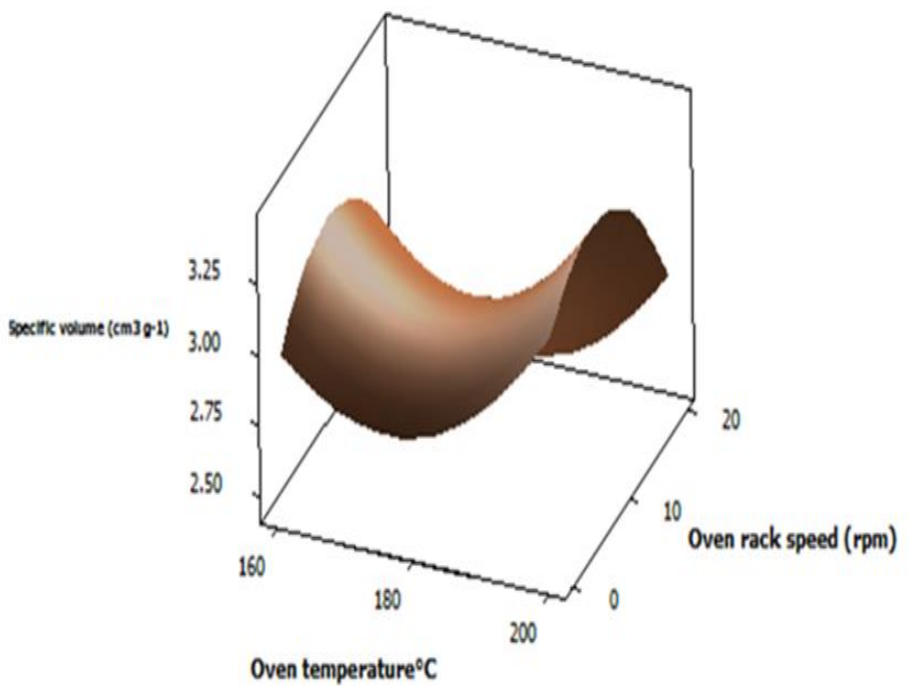

Figure 7: Surface plot of the effect of oven temperature and oven rack speed on bread specific volume.

The result showed that there was no significant difference $(p \leq 0.05)$ in the bread specific volume at $160^{\circ} \mathrm{C}$ oven temperature and $10 \mathrm{rpm}$ oven rack speed, and at $200^{\circ} \mathrm{C}$ oven temperature and $0 \mathrm{rpm}$ oven rack speed $\left(3.51 \pm 0.08 \mathrm{~cm}^{3} \mathrm{~g}^{-1}\right)$. Eq. 18 shows the quadratic regression model relating the effect of oven temperature and oven rack speed on bread specific volume.

Bread specific volume $=28.35-0.292 x_{1}+0.087 x_{2}+$ $0.0008 x_{1}^{2}-0.0034 x_{2}^{2}-0.0002 x_{1} x_{2}$

where, $x_{1}$ and $x_{2}$ are oven temperature and oven rack speed. The coefficient of determination $\left(\mathrm{R}^{2}\right)$ and $\mathrm{R}^{2}$ (adj) obtained for the model was $49.13 \%$ and $0.00 \%$. This model is not fit to predict the effect of oven temperature and oven rack speed on bread specific volume. This could imply that more factors aside oven temperature and oven rack speed might influence the bread specific volume.

\section{F. Effect of Oven Temperature and Oven Rack Speed on the Bread Density}

The effect of oven temperature and oven rack speed can be related to the density of the baked bread as shown in the surface plot in Figure 8. It was observed that the maximum density $\left(0.39 \mathrm{~g} \mathrm{~cm}^{-3}\right)$ of the baked bread occurred at an oven temperature of $160{ }^{\circ} \mathrm{C}$ and oven rack speed of $20 \mathrm{rpm}$. However, the minimum density $\left(0.26 \pm 0.01 \mathrm{~g} \mathrm{~cm}^{-3}\right)$ occurred at an oven temperature of $160^{\circ} \mathrm{C}$ and oven rack speed of $10 \mathrm{rpm}$. Although there was no wide significant difference in the densities as depicted in Table 2. The rate at which the vapour content changes during baking might be the reason for variation in the bread densities.

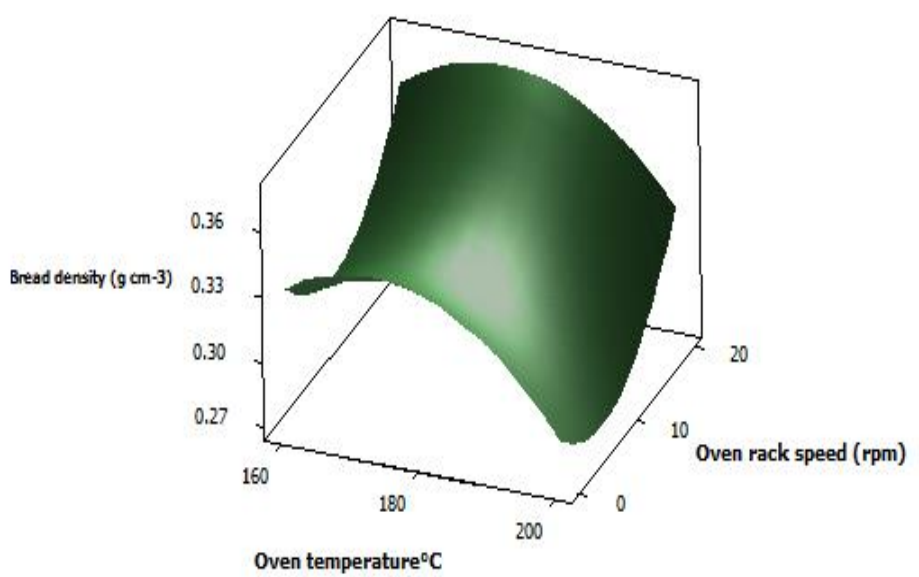

Figure 8: Surface plot of the effect of oven temperature and oven rack speed on bread density.

The minimum density obtained is close to $0.21 \mathrm{~g} \mathrm{~cm}^{-3}$ reported by Morakinyo et al. (2017) while evaluating the performance of the gas-fired oven. Eq. (19) shows the quadratic regression model relating the effect of oven temperature and oven rack speed on bread density.

Bread density $=-2.037+0.0275 x_{1}-0.00813 x_{2}-$ $0.0008 x_{1}^{2}+0.0034 x_{2}^{2}+0.0002 x_{1} x_{2}$

where, $x_{1}$ and $x_{2}$ are oven temperature and oven rack speed. The coefficient of determination $\left(\mathrm{R}^{2}\right)$ and $\mathrm{R}^{2}$ (adj) obtained for the model were $53.12 \%$ and $0.00 \%$. This model is not fit to predict the effect of oven temperature and oven rack speed on bread density. This could also indicate that some other factors might be responsible for the variation in the bread density. 


\section{CONCLUSION}

A prototype of an electric rotary oven was developed. The performance evaluation of the rotary oven showed that the oven is efficient, with a baking capacity and baking efficiency of $16 \mathrm{~kg} \mathrm{~h}^{-1}$ and $94 \%$, respectively. The oven temperature and oven rack speed had a significant influence on baking time, bread mass, bread surface area, bread specific volume and bread density. The optimum baking time for bread production was achieved in $20 \mathrm{~min}$ at $200{ }^{\circ} \mathrm{C}$ oven temperature and $10 \mathrm{rpm}$ oven rack speed. The rotary oven is recommended for small and medium scale bakeries in developing countries.

\section{REFERENCES}

Aborisade, D. O. and Adewuyi, P. A. (2014). Evaluation of PID Tuning Methods on Direct Gas-Fired Oven, International. Journal of Engineering Research and Applications, 4(03): 1-9.

American Association Cereal Chemists, (AACC). (2001). Guidelines for Measurement of Volume by Rapeseed Displacement. Baking Quality, 1e4 method 10-05.

Adegbola, A.; O. Adogbeji.; O. Abiodun and S. Olaoluwa. (2012). Design, Construction and Performance Evaluation of Low Cost Electric Baking Oven. Innovative Systems Design and Engineering, 3(11): 38-49.

Anyakoha, M. W. (2013). New School Physics: for Senior Secondary Schools. Onitsha, Nigeria: Africana First Publishers.

Bahnasawy, A. H. and Khater, E.G. (2014). Heat and Mass Balance for Baking Process, Journal of Bioprocess Biotechnology, 4 (1): 3-6.

Barua, P. B.; P. Kumar and J. L. Gaindhar. (1997). Surface Roughness Optimization of V-Process Casting through Casting Method. AFS transition 45: 733-768.

Basil, E. and Blessent, J. (2014). Development and Application of a Uniform Testing Procedure for Ovens, Pacific Gas and Electric Company Department of Research and Development Report, 4 (1): 10-25.

Bureau of Energy Efficiency (2005). Fans and Blowers, Guide book 1 for National Certification Examination for Energy Managers and Auditors, India, 93-112.

Chandrasekar, V.; K. Kannan.; R. Priyavarshini and Gayathri, R. (2015). Application of Taguchi Method in Optimization of Process Factors of Ready to Eat Peanut (Arachis hypogaea) Chutney. International Food Research Journal, 22(2): 510-516.

Clements, D. H.; J. Sarama and M. T. Battista, (2001). Length, Perimeter, Area, and Volume. Mathematics Education: An Encyclopedia. New York: Garland.

Chao-Chin, C.; C. Ho-Hsien and H. Pao-Chuan. (2008). Optimization of the Monascus purpureus Fermentation Process Based on Multiple Performance Characteristics. Journal of Grey System, 11 (2): 85-96.

Chukwuneke, J. L.; I. C. Nwuzor.; E. O. Anisiji and I. E. Digitemie. (2018). Design and Fabrication of a Dual Powered Baking Oven. Advances in Research, 1-8.
Engineering Tool Box, (2010). Fans - Calculate Air and Brake Horsepower. [online] Available at:https://www.engineeringtoolbox.com/ahp-bhp-air-brakehorsepower-d_1582.html [Accessed 21/05/2020].

Falke, R. (2016). Use the Air Changes Calculation to Determine Room cfm. https://www.contractingbusiness.com/service/article/2086824 6/use-the-air-changes-calculation-to-determine-room-cfm [Accessed 21/05/2020].

Genitha, I.; B. T. Lakshmana-Gowda and D. J. Raj. (2014). Design, Fabrication and Performance Evaluation of Domestic Gas Oven, IOSR Journal of Engineering, 2014, 4(5): 35-38.

Ho-Hsien, C.; C. Chao-Chin.; W. Han-Yan and H. Tzou-Chi. (2011). Application of Taguchi Method to Optimize Extracted Ginger Oil in Different Drying Conditions. International Conference on Food Engineering and Biotechnology, Vol. 9, IACSIT Press, Singapore.

Jefferson, D. R.; A. A. Lacey and P. A. Sadd. (2007). Crust Density in Bread Baking: Mathematical Modelling and Numerical Solutions. Applied Mathematics Modelling, 31(2): 209-225.

Kirschen, D. S.; D. W. Novotny and T. A. Lipo. (1985). On-line Efficiency Optimization of a Variable Frequency Induction Motor Drive. IEEE transactions on industry applications, (3): 610-616.

Le-bail, A.; T. Dessev.; V. Jury.; R. Zuniga.; T. Park and M. Pitroff. (2010). Energy Demand for Selected Bread Making Processes: Conventional versus part baked frozen technologies. Journal of Food Engineering, 96(4): 510-519.

Martin, E. (2018). Homemade Bread: Temperature is Key. Temperature and Bread, and Overview.https://blog.thermoworks.com/bread/homemadebread-temperature-is-key. [Accessed 21/05/2020].

Mazaheri, H.; M. Ghaedi.; M. H. Ahmadi Azqhand and A. Asfaram. (2017). Application of Machine/Statistical Learning, Artificial Intelligence and Statistical Experimental Design for the Modeling and Optimization of Methylene Blue and Cd(II) Removal From a Binary Aqueous Solution by NaturalWalnut Carbon. Royal Society of Chemistry https://doi.org/10.1039/c6cp08437k.

McCable, W. L.; J. C. Smith and P. Harricort. (1985). Mixing of Solids and Pastes Unit Operation of Chemical Engineering New York: McGraw Hill Publishing Co. 4: 834850.

Mecit H. O.; S. Serpil and S. Gulum. (2007). Optimization of Microwave Frying of Potato Slices by Using Taguchi Technique. Journal of Food Engineering 79 (1): 8391.

Mondal, A. and Datta, A. K. (2008). Bread baking - A Review. Journal of Food Engineering, 86: 465-474.

Morakinyo, A. T.; B. Omidiji and H. Owolabi, (2017). Development and Optimization of Operational Parameters of a Gas-Fired Baking Oven. Leonardo Journal of Sciences, (31): 45-64. 
Okafor-Basil, E. (2014). Simple Design of a DualPowered Domestic Oven, International Journal of Engineering and Technology, 4(5): 1-13.

Penga, W. L.; H. Mohd-Nasira; S. H. M. Setaparb; A. Ahmad and D. Lokhatd. (2019). Optimization of Process Variables using Response Surface Methodology for Tocopherol Extraction from Roselle Seed Oil by Supercritical Carbon dioxide. Industrial Crops \& Products, 143(1):1-11. https://doi.org/10.1016/j.indcrop.2019.111886

Sanusi, M.S.; R. Akinoso.; N. Danbaba and M.O. Sunmonu. (2020). Effect of Processing Parameters on the Milling Quality of Brown Rice using Taguchi Approach. American Journal of Food Technology, 15 (2), 62-68. DOI: 10.3923/ajft.2020.62.68.

Stadler, M.; M. B. Schmitz.; P. Ragg.; D. M. Holman and R. Brionnaud. (2012). Aeroacoustic Optimization for Axial Fans with the Lattice-Boltzmann Method. In ASME Turbo Expo 2012: Turbine Technical Conference and Exposition. American Society of Mechanical Engineers Digital Collection, 743-752.

Ureta, M. M.; D. F. Olivera and V. O. Salvadori. (2017). Influence of Baking Conditions on the Quality Attributes of Sponge Cake. Food Science and Technology International, 23(2): 156-165.

Therdthai, N.; W. Zhou and T. Adamczak. (2002). Optimisation of the Temperature Profiles in Bread Baking. Journal of Food Engineering, 55(1): 41 - 48.

Zheleva, I. and Kambourova, V. (2005). Identification of Heat and Mass Transfer Processes in Bread during Baking, Thermal Science, 9(2): 73-86. 